\title{
Analysis of the susceptibility to COVID-19 in pregnancy and recommendations on potential drug screening
}

\author{
Xiaoxuan Zhao ${ }^{1} \cdot$ Yuepeng Jiang ${ }^{2} \cdot$ Yang Zhao $^{3} \cdot$ Hongyan $\mathrm{Xi}^{1} \cdot$ Chang Liu $^{2} \cdot$ Fan $\mathrm{Qu}^{4} \cdot$ Xiaoling Feng $^{5}$
}

Received: 11 March 2020 / Accepted: 2 April 2020 / Published online: 23 April 2020

(C) Springer-Verlag GmbH Germany, part of Springer Nature 2020

\begin{abstract}
To analyze the susceptibility of SARS-CoV-2 in pregnancy and the drugs that can be used to treat pregnancy with COVID-19, so as to provide evidence for drug selection in clinic. By reviewing the existing literature, this paper analyzes the susceptibility of pregnant women to virus, especially to SARS-CoV-2, from the aspects of anatomical, reproductive endocrine and immune changes during pregnancy and screens effective and fetal-safe treatments from the existing drugs. The anatomical structure of the respiratory system is changed during pregnancy, and the virus transmitted by droplets and aerosols is more easily inhaled by pregnant women and is difficult to remove. Furthermore, the prognosis is worse after infection when compared with non-pregnancy women. And changes in reproductive hormones and immune systems during pregnancy collectively make them more susceptible to certain infections. More importantly, angiotensin-converting enzyme (ACE)-2, the SARS-CoV-2 receptor, has been proven highly increased during pregnancy, which may contribute to the susceptibility to SARS-CoV-2. When it comes to treatment, specific drugs for COVID-19 have not been found at present, and taking old drugs for new use in treating COVID-19 has become an emergency method for the pandemic. Particularly, drugs that show superior maternal and fetal safety are worthy of consideration for pregnant women with COVID-19, such as chloroquine, metformin, statins, lobinavir/ritonavir, glycyrrhizic acid, and nanoparticle-mediated drug delivery (NMDD), etc. Pregnant women are susceptible to COVID-19, and special attention should be paid to the selection of drugs that are both effective for maternal diseases and friendly to the fetus. However, there are still many deficiencies in the study of drug safety during pregnancy, and broad-spectrum, effective and fetal-safe drugs for pregnant women need to be developed so as to cope with more infectious diseases in the future.
\end{abstract}

Keywords New coronavirus disease $\cdot$ Pregnancy $\cdot$ Virus susceptibility $\cdot$ Antiviral treatment $\cdot$ Fetal safety

Fan Qu

syqufan@zju.edu.cn

Xiaoling Feng

Doctorfx1@163.com

1 Heilongjiang University of Chinese Medicine, Harbin 150040, China

2 Zhejiang Chinese Medical University, Hangzhou 310053, China

3 Hebei College of Traditional Chinese Medicine, Shijiazhuang 050000, China

4 Women's Hospital, School of Medicine, Zhejiang University, Hangzhou 310006, China

5 First Affiliated Hospital of Heilongjiang University of Chinese Medicine, Harbin 150040, China

\section{Introduction}

Since the end of 2019, the 2019 new coronavirus disease (COVID-19) that occurred in Wuhan, Hubei Province has posed a serious threat to China and even the world. In January 30, 2020, COVID-19 was declared a public health emergency of international concern (PHEIC) by WHO. The novel coronavirus is officially classified as SARS-CoV-2, known as "severe acute respiratory syndrome coronavirus 2" [1]. So far, 77,262 cases have been confirmed in China and nearly 2000 cases of infection in other countries. Although the isolation, gene sequence, and structural analysis of the virus have been completed, there is still no specific drug against it. Since drug development needs a long period, it cannot meet the urgent needs of the moment. Therefore, using the existing drugs to cut off the above process of the virus is expected to 
make a breakthrough in a short time, on the premise of understanding the invasion, replication, and release mode of the virus. There is a special group in this outbreak, pregnant women, which deserve our great attention because of the physiological changes during pregnancy that make them more susceptible to virus. Previous epidemiological evidence strongly suggests that pregnant women have a higher risk of serious illness and death from viral infections [2] during pandemics such as influenza and ebola [3, 4]. In addition, viral infections tend to result in miscarriage, preterm, and so on. And because of the existence of fetus and placenta, pregnancy brings us unique pharmacological challenges. As discussed in the literature of the past two decades, pregnant women are indeed "drug orphans" [5]. The number and efficacy of drugs that can be used to treat pregnant women who are afflicted with other diseases are extremely limited. And it is often difficult to quantify the passing degree of a drug between mother and fetus and its side effects on fetus. Therefore, it is of great significance to understand why pregnant women are at higher risk during outbreaks of infectious disease, and then design appropriate prevention methods and treatment on due consideration of pregnancy. Thus, we reviewed the existing literature and summarized the etiological features of SARS-CoV-2; analyzed the susceptibility of pregnant women to virus from respiratory, immune, and endocrine system changes; and proposed the therapeutic drugs that could be used to treat pregnant women with COVID-19, so as to provide information for the selection of drugs for clinical treatment.

\section{Etiological features of SARS-CoV-2}

Coronavirus is a plus-stranded linear RNA virus with an envelope (or capsule) and is the largest RNA virus. Belonging to the order Nidovirales, family Coronaviridae, and the subfamily Orthocoronaviridae, there are four genera of coronavirusAlphacoronavirus, Betacoronavirus, Deltacorona virus, and Gammacoronavirus [6-8]. The envelope of coronavirus is composed of bilayer lipid and transmembrane protein, and the spinous processes outside the membrane are crown-like under the electron microscope. Its nucleocapsid consists of a positive-strand RNA and a capsid protein, with a helically symmetric structure. The genome size of coronavirus is $26-$ $32 \mathrm{~kb}$, and its structure is highly conserved, as follows: $5^{\prime}$ leading sequence-replicase-spike (S) protein-envelope (E) protein-membrane $(\mathrm{M})$ protein-nucleocapsid (N)-3' poly (a). About $67 \%$ of its genome is used to code for replication enzymes, and the rest is used to code for structural proteins and helper proteins, as shown in Fig. 1 [9, 10]. There are seven coronaviruses currently infecting humans, of which the SARS-CoV-2 is the third coronavirus to cause a major epidemic, after severe acute respiratory syndrome (SARS) and Middle East respiratory syndrome (MERS). At present, there

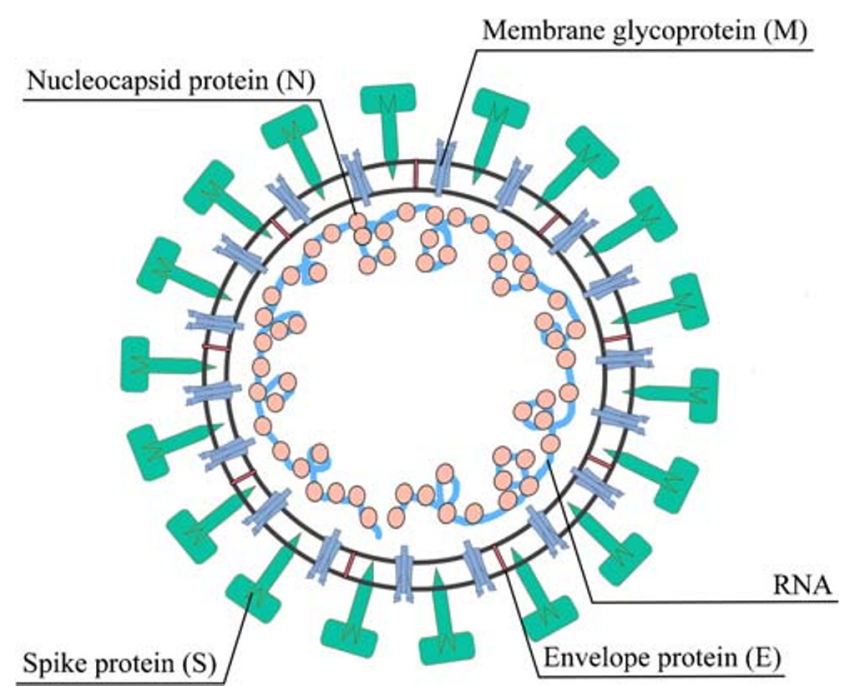

Fig. 1 Schematic diagram of the structure of coronavirus

is only one complete $2019 \mathrm{nCoV}$ genome $(29,870 \mathrm{bp}$, excluding poly (a) tail) (No. mn908947) in GenBank [11]. Lu and his colleagues [12] found that although SARS-CoV-2 is more similar to bat-sl-covzc45 and bat-sl-covc21 (about $88 \%$ of the genome sequence homology) derived from two bat-like coronaviruses, compared with SARS-CoV-1 (about 79\%). And the homology model showed that the structure of receptor binding region of SARS-CoV-2 and SARS-CoV-1 is more similar, suggesting a similar pathogenesis of the two viruses. Scholars have confirmed that both SARS-CoV-2 and SARS$\mathrm{CoV}-1$ enter the host cell by binding their S proteins to ACE2 receptors located on the surface of the host cells. On February 19, 2020, researchers from the University of Texas and NIH used cryoelectron microscopy to demonstrate the molecular structure of the neocoronavirus S protein for the first time, and they found that the affinity between neocoronavirus and ACE2 was 10 20 times than that of SARS-CoV-1 [13]. On the same day, Zhou Qiang's team from West Lake University published the results online on the preprint platform BioRxiv, successfully analyzing the full-length structure of ACE2, the cell receptor of SARS-CoV-2 [14], and Zhou's team found that ACE2 exists as a dimer, with both open and closed conformations that contain a mutual recognition interface with SARS-CoV-2. On February 21, three biological research teams published online the three-dimensional crystal structure of the $\mathrm{S}$ protein receptor-binding region (RBD) of SARS$\mathrm{CoV}-2$ and the ACE2 receptor [15]. After the S protein binds to ACE2 receptor, it is cleaved in S1 region by cell protease TMPRSSs to expose the fusion region located in S2 region, thus facilitating the fusion of virus envelope and cell membrane system, helping the viral nucleocapsid enter the cytoplasm. In terms of nucleotide order, SARS-CoV-2 inserts four amino acids at protease cleaving sites between $\mathrm{S} 1$ and $\mathrm{S} 2$, which can make cleaving more efficient. After entering the 
cell, the virus uses the cell's own protein synthesis system to produce replicase, other structural proteins, and helper proteins.

\section{Reasons for pregnant women's susceptibility to the virus}

Pregnant women are more susceptible to the virus and show a worse prognosis than non-pregnant women. Epidemiological data show that the susceptibility, morbidity, and mortality of pregnant women to influenza virus are significantly increased compared with non-pregnant women. In the outbreak of the influenza during 1957-1958, the mortality of pregnant women was $10 \%$, which was twice as high as that of non-pregnant women [16]. Furthermore, statistics show that of the 484 people in USA who died from the 2009 H1N1 influenza, 28 (5. $8 \%$ ) were pregnant women, who accounted for only $1 \%$ of the US population [17]. During the outbreak of SARS in 2003, several small clinical reports reported that pregnant women infected with SARS had worse outcomes than non-pregnant women. For example, a hospital in Hong Kong reported the infection in 10 pregnant women and 40 non-pregnant women, of which 3 (30\% maternal mortality) of the pregnant women died of SARS, and no deaths occurred in the non-pregnant group $(P=0.006)$ [17]. Through these statistics, we can clearly find that pregnant women are at high risk of viral infectious diseases, which have been proved to be closely related to physiological changes in the respiratory, circulatory, secretory, and immune systems during pregnancy.

\section{Changes in respiratory system}

A series of physiological changes occur in the maternal respiratory system during pregnancy. Anatomically, the effects of progesterone and relaxants in the first trimester of pregnancy can lead to the relaxation of ligaments in the ribs [18]. And the diaphragm will move up as the uterus grows. Besides, the subcostal angle and transverse diameter of the thoracic cavity will increase further in the third trimester. The above anatomical factors, together with the decreased compliance of chest wall, eventually lead to a 20 to $30 \%$ reduction in functional residual capacity (FRC) [19], which makes the mother prone to hypoxia, subsequently compensated by increased tidal volume and hyperventilation. In addition, elevated progesterone can be transmitted through estrogen-dependent progesterone receptors in the hypothalamus, thus stimulating the respiratory center and increasing tidal volume by $50 \%$ compared with non-pregnancy [20]. Hyperventilation causes pregnant women to inhale more air within the same period of time. If SARSCoV-2 is in the air, pregnant women are more likely to get the disease than ordinary people and are infected by droplets, aerosols, and other means. In addition, the changes of nasal mucosa mediated by progesterone during pregnancy may lead to the adhesion of the virus in the upper respiratory tract and make it difficult to be cleared [21, 22].

Physiological changes in pregnant women not only increase their susceptibility to the virus, but also increase the severity of the disease. According to epidemiological statistical studies, the indicators used to assess the severity of the disease themselves are directly affected by pregnancy [23]. The cardiovascular changes, the increase in metabolic rate and oxygen consumption, the decrease in functional residual capacity, and the mismatch between basic ventilation and perfusion, all of these factors caused by pregnancy are easy to lead to the occurrence of hypoxic respiratory failure in women after infection with SARS-CoV-2 [24]. On the other hand, if virus infection occurs, pulmonary vascular resistance will increase, which may lead to pulmonary hypertension and heart failure [25]. According to current statistics, a significant proportion of deaths with COVID-19 are due to dyspnea. While the incidence of physical dyspnea in the third trimester of pregnancy is $50-70 \%$. Without doubt, SARS-CoV-2 infection will undoubtedly worsen the degree of breathing difficulties.

\section{Changes in the immune system}

A successful pregnancy is the mother's tolerance to the allogeneic fetus. Because nearly half of the embryo's genome comes from the father, which are then expressed as paternal antigens that can be recognized by the maternal immune system as foreign antigens. Therefore, the mother will undergo a series of complicated processes to ensure the acceptance of fetus [26], and these immune changes may increase the mother's susceptibility to certain infectious diseases [27]. Many scholars believe that during pregnancy, Th2/Th1 is deviated to Th2, while in abortion, it is reversed [28, 29]. The transfer of immunity to Th2 is the cause of changes in the peripheral response to respiratory virus infection [30] and autoantigen [31]. Danza et al. found that the total number of $\mathrm{CD} 3+\mathrm{T}$ cells in the blood decreased [32]. Moreover, the surge in estrogen and progesterone in the first trimester of pregnancy leads to reversible degeneration in thymus, which may account for the decrease in $\mathrm{CD} 4+$ and $\mathrm{CD} 8+\mathrm{T}$ cells [33]. Besides, in order to study the relationship between pregnancy and virus immune, Thomas et al. [34] assessed longitudinal changes among more than 50 participants at three time points during pregnancy and two time points during postpartum, such indicators are observed as white blood cell count, analysis of the function of NK cells and $\mathrm{CD} 4^{+} \mathrm{T}$ cell response, determination of cytokines in maternal blood, level of defensins, steroid hormones, and so on. The results showed that compared with postpartum, the late gestation was characterized by a decreased number and activity in NK cells and T cells, which may affect the viral clearance rate and lays a foundation for the onset and deterioration of infectious 
diseases [35, 36]. Thus, in addition to a decrease in the number of $T$ cells in the blood during pregnancy, the activity of these cells was significantly reduced even in the absence of a significant preference for the Th2 phenotype [37-39], all of which contributes to the susceptibility of pregnant women to the virus.

\section{The expression of ACE2 is increased during pregnancy}

ACE is the core of the renin-angiotensin system (RAS) and has long been considered a key regulator of blood pressure in mammals. The presence of its homolog ACE2 in humans was not confirmed until 50 years after ACE was discovered [40]. Different from ACE, ACE2 functions as a carboxyl monopeptidase to lyse the single residues of ANG I to generate the single residues of ANG 1-9 and ANG II which is then decomposed as ANG 1-7 [41]. ANG 1-7 is a bioactive peptide with vasodilatory activity that can counteract the contractile effects of ANG II, so ACE2 is thought to modulate the effect of the RAS on vascular tension [42, 43].

With the development of medical science and technology, ACE2 is not only considered as an angiotensinrelated peptide. In recent studies, scholars believe ACE2 is the "doorknob" for SARS-CoV-2 entering the door of the host cells [44], and the upregulation of ACE2 is likely to increase the susceptibility of COVID-19. Studies have shown that smoking is also a susceptibility factor for SARS-CoV-2, and analysis of gene chips in smoking patients has found that ACE2 expression is upregulated when comparing with non-smoking patients [45], which is consistent with clinical evidence. In the same way, a high expression of ACE2 in pregnant women also increases the susceptibility of pregnant women to SARSCoV-2. Brosnihan et al. [46] proposed an increased level of ACE2 in pregnant women's kidneys. And Joyner et al. [47] also reported an increase in immunocytochemical staining of ANG 1-7 and ACE2 in the kidney of pregnant rats, indicating that this increase was gradual in both cortex and medulla during pregnancy. Besides, Levy et al. found that the amount of ACE2 mRNA in the kidney, placenta, and uterus increased significantly during pregnancy, resulting in a twofold increase in total compared to non-pregnant women [48]. It is speculated that increased level of ACE2 is able to regulate blood pressure during pregnancy, and this adaptation may be a favorable condition for SARS-CoV-2 infection. In addition, ACE2 is not only a receptor, but also involved in post-infection regulation, including immune response, cytokine secretion, and viral genome replication. Therefore, the relationship between upregulation of ACE2 and SARS-CoV-2 in pregnancy needs to be further studied, and new targets for drug development are expected to be found from these aspects.

\section{Effects of viral infection on the fetus}

There has been considerable concern about the effects of SARS-CoV-2 infection during pregnancy on the fetus or newborn. No evidence has been found that the development of COVID-19 in the third trimester of pregnancy can lead to severe adverse outcomes in fetus and the newborn arose from infections that may be caused by vertical intrauterine transmission. Chen et al. [49] retrospectively analyzed the clinical data of 9 labor-confirmed COVID-19 pregnant women and explored the potential of vertical transmission of the virus. The results showed that the clinical characteristics of these patients with SARS-CoV-2 infection during pregnancy were similar to those of non-pregnant adult that previously suffered from COVID-19, and that the SARS-CoV-2 test of amniotic fluid, umbilical cord blood, neonatal throat swabs, and breast milk samples of 6 patients were negative. Recently, Dr. Stephen Morse, an epidemiologist at the Columbia University's mailman school of public health, says: "Based on previous observations of pregnant women with MERS and SARS, although limited in number, intrauterine coronavirus transmission from mother to fetus has never been confirmed," when he is asked about babies recently diagnosed with 2019-nCoV infection [49].

However, even if we do not find proofs of vertical transmission, it is not enough to make us relax. Because the present study shows that even if the virus infection is absent in the placenta, the mother's response to infection tends to promote the fetus inflammatory response, which is defined as the fetal inflammatory response syndrome (FIRS), characterized by high levels of inflammatory cytokines in placenta, such as IL-1, IL-6, IL-8, and TNF- $\alpha$ but a lack of culturable microorganisms. These cytokines have been shown to affect the central nervous system and circulatory system and tend to cause fetal abnormal morphology in animal models, including ventricular expansion and bleeding [50-52]. In addition to the morphological effects on the fetal brain, the presence of FIRS has been associated with an increased risk of diagnosis of autism, schizophrenia, neurosensory deficits, and late-stage psychosis [53, 54]. To better understand the mechanisms by which maternal infections cause neurodevelopmental and psychological abnormalities in offspring, several groups have conducted extensive studies. Animal models, including rodents, rabbits, and sheep, were injected with TLR ligands to determine whether inflammation downstream of the TLR signal pathway affected development and offspring behavior. Both LPS (TLR4 ligand) and poly (I:C) (TLR3 ligand) treatments during pregnancy lead to deficits in pre-pulse inhibition (PPI), social interaction, and progeny learning [55]. It is not difficult to find pregnant women in the state of infection, whether or not there is vertical transmission, will bring serious effects on the fetus. Therefore, active treatment should be given when pregnant women are infected with SARS-CoV-2 
so as to prevent more serious effects on the future development of the mother and fetus.

\section{Treatment}

The lack of cellular structure of the virus contributes to its great variability, which also makes people still weak in antiviral treatment. Due to the lack of cell structure and the strong variability of virus, people still have difficulty in antiviral treatment. Since 2013, the FDA has approved only 12 drugs to treat viral infections, 10 for hepatitis $\mathrm{C}$ virus (HCV) and $\mathrm{HIV}$, one for cytomegalovirus (CMV), and one for influenza virus (IFV). Currently, there is no specific drug for sarsSARScCovV-2. At present, people only have to choose existing drugs based on the past experience of antiviral and strive to develop vaccines or direct-acting antiviral drugs or hostdirected therapies at the same time [56]. However, due to the presence of the fetus, many antiviral drugs are prohibited during pregnancy because of their proven teratogenicity. For example: ribavirin is listed as an X-grade drug in the Federal Drug Administration (FDA), indicating that it is prohibited during pregnancy. Ribavirin's FDA (Federal Drug Administration) (www.fda.gov) pregnancy drug safety rating is $\mathrm{X}$, indicating that its use is contraindicated for pregnant women. Susan S. Roberts et al. [57] conducted a 5-year study with the goal of observing the live births of 131 mothers who were directly (mother) exposed to ribavirin. After 5 years, 49 babies were born alive, and congenital malformations are as follows: torticollis (2), hypospadias (1), polydactyly and a neonatal tooth (1), glucose 6 phosphate dehydrogenase deficiency (1), ventricular septal defect, and cyst of 4th ventricle of the brain (1). Clearly, ribavirin should be banned during pregnancy. In addition, many prescription drugs lack reliable data to support their safety in treating pregnancy-related conditions [58]. In fact, far fewer clinical drug trials are conducted during pregnancy than in any other major health field [59]. In order to treat pregnancy combined with COVID-19 as quickly, effectively, and safely as possible, we have proposed some drugs that might be used to treat COVID-19 based on the existing evidence, so as to provide convenient evidence for clinicians to choose drugs.

\section{Chloroquine, chloroquine phosphate, and hydroxychloroquine}

Chloroquine was first synthesized in 1934 by Hans Andersag in Bayer, Germany, through structural modification of the oldest antimalarial drug, quinine. Chloroquine phosphate, a FDA-approved antimalarial drug, has been used clinically for more than 70 years. Hydroxychloroquine is a new antimalarial drug developed by scientists on the basis of chloroquine in 1944. The difference between the two drugs is that one ethyl in chloroquine is replaced by one hydroxyethyl in hydroxychloroquine. Though the two drugs share similar therapeutic effects, the side effects of hydroxychloroquine are significantly less than that of chloroquine [60]. At present, the main clinical applications are chloroquine phosphate and hydroxychloroquine.

Previous studies have clearly suggested that chloroquine has shown immunomodulatory and broad-spectrum antiviral effects, and such mechanisms ensure its therapeutic effects in a variety of infectious diseases, and has begun to show new applications of this old drug, and COVID-19 may also in its therapeutic range. Evidence and clinical trials have confirmed the inhibitory effect of chloroquine on HIV/AIDS, MERS$\mathrm{CoV}$, SARS-CoV, and other viruses. Moreover, the dose of antiviral is lower than the blood concentration of the treatment of malaria, and no toxicity was found to host cells [61]. Martin et al. [62] showed that the inhibitory effect of chloroquine on cells of SARS-CoV infection can be demonstrated before or after the cells are exposed to the virus, which means that chloroquine shows an effect both on prevention and on treatment of SARS-CoV. Firstly, chloroquine is an alkaline compound whose non-protonated parts enter cells and are protonated and concentrated in acidic organelles with low PH (such as endosomes, golgi vesicles, and lysosomes), thereby increasing the $\mathrm{PH}$ in the nucleus and blocking ph-dependent replication of coronavirus retroviruses [63]. In addition, the drug can interfere with the terminal glycosylation of the cell receptor ACE2, which has been identified as a functional cellular receptor of SARS-CoV [64]. And this virus-receptor binding can be inhibited and make the infection invalidated. Last but not least, chloroquine has also been found to have an immunomodulatory effect. It can inhibit the production and release of TNF- $\alpha$ and IL- 6 and has been used in the treatment of autoimmune diseases such as rheumatoid arthritis and lupus erythematosus [65]. In the middle and late stage of SARSCoV infection, TNF- $\alpha$ and IL- 6 concentrations are correlated with the severity of the disease, so the anti-inflammatory effect of chloroquine can also reduce immune lesions. It has been reported that the use of hydroxychloroquine in systemic lupus erythematosus leads to defective differentiation in Th17 cells, and the expression of cytokine IL-17 was also limited to some extent, which is a potential evidence of chloroquine in reducing cytokine storm [66]. These trials were sufficient to support the therapeutic effect of chloroquine on COVID-19. Wang et al. [67] demonstrated that chloroquine functioned at both entry and at post-entry stages of the 2019-nCoV infection in Vero E6 cells by time-of-addition assay. Besides its antiviral activity, chloroquine has an immune-modulating activity, which may synergistically enhance its antiviral effect in vivo.

We collected some evidences for the use of chloroquine in pregnancy combined with COVID-19. Although chloroquine is classified as class $\mathrm{C}$ in the FDA for pregnancy, the effect of chloroquine on pregnancy is proved to be mild. Klumpp et al. 
[68] believed that in the 20 years since the advent of chloroquine, an estimated 1 billion people have used chloroquine, including pregnant women. They have never found reports of fetal damage, and the agencies responsible for malaria control in malaria-endemic areas have not banned the use of antimalarials by pregnant women. And records in WHO do not show any adverse effects of chloroquine on pregnancy, childbirth, or newborns. In addition, regarding the pregnancy safety of hydroxychloroquine, Yusuf Cem Kaplan et al. [69] conducted a meta-analysis that included seven cohort studies and one randomized controlled trial, involving 1820 infants. The meta-analysis reported no significant increases in rates of major congenital (OR 1.13, 95\% confidence interval (CI) 0.59, 2.17), craniofacial (OR $0.62,95 \%$ CI $0.13,3.03$ ), cardiovascular (OR 1.06, 95\% CI 0.29, 3.86), genitourinary (OR 1. 8, $95 \%$ CI $0.42,4.53$ ), nervous system malformations (OR 1.81, $95 \%$ CI 0.31, 10.52), stillbirth (OR 0.69, 95\% CI 0.35, 1.34), low birth weight (OR $0.69,95 \%$ CI $0.21,2.27$ ), or prematurity (OR 1.75, 95\% CI 0.95, 3.24). Based on this evidence, we speculate that hydroxychloroquine has the potential to be an effective drug in pregnancy with COVID-19.

\section{Interferon}

Type I interferon (I-IFN) mainly includes IFN- $\alpha, \beta, \kappa$, and $\lambda$, of which IFN- $\alpha$ and IFN- $\beta$ are currently the main clinical interferons for anti-CoVs. Studies have shown that I-IFN has antiviral effects on various cell models, such as embryonic kidney cells (fRhK-4) of rhesus monkey and monkey kidney cells (Vero-E6), etc. [70]. In the study of infected macaques, preventive treatment of IFN- $\alpha$ significantly reduced replication of SARS virus, expression of viral antigen in type I alveolar epithelium, and lung injury [71]. The antiviral effect of IIFN was clearly demonstrated not only in animal experiments but also in human trials. In an open-label, non-randomized clinical trial of 22 SARS patients, nine were subcutaneous injected with I-IFN, and the results showed that all nine patients survived with fewer side effects [72]. IFN- $\beta 1$ a shows stronger antiviral activity than IFN- $\alpha$, and there was evidence that when IFN- $\alpha$ begins to show anti-SARS-CoV effects at $1000 \mathrm{IU} / \mathrm{mL}$, recombinant human IFN- $\beta 1 \mathrm{a}$ is able to inhibit SARS-CoV activity strongly [73]. Besides, a retrospective study [74] showed that there was no significant difference in case fatality rate between IFN- $\beta 1 \mathrm{a}$ and IFN- $\alpha 2 \mathrm{a}$ in patients infected with MERS $(P=0.24)$. When taking these proofs into consideration, we speculated that I-IFN may play a role in clinical treatment of COVID-19, and IFN- $\beta 1$ a may be more preferable.

Is I-IFN safe enough for women during pregnancy? Yazdani BP et al. [75] conducted a meta-analysis to observe whether I-IFN has adverse effects on patients with primary thrombocytopenia (ET) during pregnancy. A total of 63 case reports of IFN- $\alpha$ direct exposure during pregnancy were included, of which 40 were diagnosed with ET, while 71 patients with ET not receiving any medication during pregnancy were taken as controls. The results showed that none of the 63 patients who received IFN- $\alpha$ during pregnancy had major malformations or stillbirths, and that IFN- $\alpha$ did not significantly increase the risk of malformations, miscarriages, stillbirths, or premature births. Thus, in the case of COVID-19 during pregnancy, IFN is expected to be effective and safe.

\section{Lopinavir/litonavir}

At present, lopinavir/ritonavir is recommended for antiviral therapy of COVID-19 in many treatment schemes in China. Lopinavir/ritonavir used to combat HIV [76]. Lopinavir can prevent the division of HIV Gag-Pol, and litonavir can inhibit the activity of HIV protease by acting on aspartyl proteases of virus, making it unable to shear the precursor protein of GagPol polymerase. The combination of lopinavir and litonavir can inhibit the proliferation of HIV virus by producing nonreproducible particles in immature forms during the virus replication process [77]. Because lopinavir/ritonavir has a clear binding site with SARS-CoV, and the SARS-CoV-2 sequence shows a high homology with SARS-CoV-1, lopinavir/ ritonavir is strongly recommended for the treatment of COVID-2019. Shen Lin et al. [78] established the structural model of protease $\mathrm{C} 30$ of SARS-CoV-2 and papain-like virus protease through homologous modeling, and then docked ritonavir and lopinavir with the protease model respectively. Through docking, 100 poses were found when docking ritonavir to CEP_C30, with the libdock score of the optimal pose 192.346. Eighty-eight poses were found when docking lopinavir to CEP_C30, with the libdock score of the optimal pose. The results suggest that the therapeutic effect of ritonavir on COVID-19 may be mainly due to its inhibition of coronavirus endopeptidase $\mathrm{C} 30$. In addition, during the outbreak of SARS, scholars [77] in Hong Kong, China, used lopinavir/ ritonavir and ribavirin to treat 41 patients. The results showed that compared to the 111 patients treated only with ribavirin, patients treated with combination therapy had a lower risk of adverse events such as ARDS or death (2.4\% vs $28.8 \%)$. Thus, we can find that the addition of lopinavir/ritonavir shows promise to benefit the treatment of COVID-19.

So, can lopinavir/ritonavir be used in pregnant women? An open-label, randomized controlled trial by Koss CA et al. [79] involved 356 pregnant women infected with HIV. Lopinavir/ ritonavir or efavirenz was randomly administered at 12 to 28 weeks of pregnancy. Univariate and multivariate logistic regressions were used to analyze the potential risk factors for preterm labor (less than 37 weeks). The results showed that lopinavir/ritonavir was not associated with an increased risk of preterm compared with efavirenz, except for nutritional factors $(\mathrm{OR}=1.12,95 \%$ CI $0.632 .00, p=0.69)$. Besides, Martinez et al. [80] analyzed 955 women exposure to 
lopinavir/litonavir during pregnancy. Result showed that the prevalence of birth defects in infants with prenatal exposure to lopinavir/litonavir was not significantly different from that in internal or external controls. These data provide patients and clinicians with reliable information on the safety of lopinavir/ ritonavir in treating pregnant women with COVID-19. Thus, lopinavir/ritonavir is safer than other direct antiviral drugs. In addition, lopinavir/ritonavir is the preferred antiviral therapy for pregnancy with COVID-19, according to the second edition of the strategy recommendations for management of COVID-19 in pregnancy (published at Huazhong University of Science and Technology Union Hospital). So this drug deserves our full consideration in the treatment of COVID19 during pregnancy.

\section{Host-directed therapy}

HDT (host-directed therapy) refers to a variety of therapeutic approaches that work without direct anti-infection in the fight against infectious diseases [81]. Its goal is to "intervene the mechanism of pathogen infection, activate the body's protective immune response, suppress the overactive inflammatory response, and balance the immune response of diseased parts." Clinical data indicate that COVID-19 patients of severe type present with cytokine storms, which are characterized by elevated levels of IL-2, IL-7, IL-10, granulocyte colonystimulating factor, and TNF- $\alpha$, resulting in pathological damage to multiple organs of the body [82]. In acute infections, HDT is expected to inhibit overactive inflammatory responses, the same as in COVID-19. Alimuddin Zumla [83] pointed out that HDT has been proved to be safe and effective, of which metformin, glitazone, and atorvastatin are commonly used drugs [84]. The application of HDT may reduce immunopathology and enhance immune response, which is hopeful in reducing mortality in patients with COVID-19. Studies have shown that metformin increases the production of mitochondrial ROS and enhances autophagy in macrophages [85]. Zmijewski JW et al. [86] treated mice exposed to LPS with metformin and found that metformin inhibited the level of mitochondrial complex I in the lungs and reduced the severity of lung damage. And mitochondrial complex I plays a vital role in regulating toll-like receptor 4-mediated activation of neutrophils. Thus, we concluded that one of the mechanisms that metformin takes effect in acute inflammation is to inhibit mitochondrial complex I. So, can metformin be considered when pregnant women choose an HDT drug? Gilbert et al. [87] gave the answer. They included eight studies involving 200 women exposed to metformin in the first trimester of pregnancy. The results showed that exposure to metformin in the first trimester of pregnancy was not associated with an increased incidence of major malformations $[\mathrm{OR}=0.50$ (95\% CI: 0.15, 1.60)]. Li et al. [88] included 11 studies involving 2712 women with gestational diabetes. The results showed that metformin could significantly reduce adverse maternal and neonatal outcomes such as gestational hypertension, hypoglycemia, neonatal intensive care, and so on. As a result, it is a safe and effective alternative or complementary therapy for insulin in women with gestational diabetes. And such safety is also promising for pregnant women with COVID-19.

Statins, another drug in the HDT regimen, are able to induce autophagy and phagocytic maturation by activating receptor of peroxisome proliferator-activated receptor $\gamma$ and transforming growth factors $\beta[88]$ and play an antiinflammatory role in influenza and other lung injury diseases [89]. A trial involving 477 cases exposed to simvastatin or lovastatin during pregnancy showed the incidence of congenital abnormalities in neonates was $3.8 \%$, similar to the average rate of 3\% [90]. Although the number of reports is relatively small, there is no evidence of an increase in congenital deformities in children exposed to simvastatin or lovastatin before birth, compared with the general population. Therefore, such drugs as metformin and statins are much friendlier for pregnancy. Alimuddin Zumla [91] pointed that metformin, statins, can be used as adjuvant with cyclosporine, lobinavir/ritonavir, interferon- $1 \mathrm{~b}$, ribavirin, monoclonal antibodies, and antiviral peptides targeting SARS-CoV-2, thereby reducing the use of antiviral drugs and reducing side effects. Therefore, the application of HDT is very suitable for pregnant women with COVID-19.

\section{Glycyrrhizin}

A 2016 international study showed that up to $60 \%$ of pregnant women use herbal-based alternative medicines [92]. Licorice is one of the most frequently used drugs in China. Glycyrrhizin is considered to be the main bioactive ingredient in licorice, which is then metabolized to glycyrrhetinic acid. It shows anti-inflammatory, antiviral, antiallergic, and immuneregulating effects in various studies [93]. In recent years, glycyrrhizin has made progress in the treatment of hepatitis B, AIDS, SARS, and other viral infectious diseases. Chen et al. [94] found that glycyrrhiza had anti-SARS-CoV activity by means of neutralization and plaque determination. And scientists from the clinical center of Frankfurt University in Germany compared the antiviral effects of ribavirin, 6azaguanosine, pyrazofuran, mycophenolate acetate, and glycyrrhizin on two SARS patients [95]. Results showed that glycyrrhizin had the strongest inhibitory effect on SARS-CoV replication. The half maximal effective concentration (EC50) was $300-600 \mu \mathrm{g} / \mathrm{ml}$ and the half maximal cytotoxic concentration $(\mathrm{CC} 50)>20,000 \mu \mathrm{g} / \mathrm{ml}$. Furthermore, glycyrrhizin can not only inhibit virus replication but also impair virus adsorption and membrane penetration in the early stage of virus replication, which is expected to make it a specific drug for the treatment of COVID-19. 
Maternal and fetal safety of glycyrrhizin is a major concern in pregnant women with COVID-19. One study showed that no reproductive or phylogenetic toxicity was found in rats exposed to licorice water extract of $500-2000 \mathrm{mg} / \mathrm{kg}$ from 2 weeks before mating to the 19th day of pregnancy. In human experiments, Strandberg et al. [96] divided 107 pregnant women who had exposed to glycyrrhizin into three groups according to the exposure dose: low $(<250 \mathrm{mg} /$ week $)$, medium (250-499 mg/week), and high (500 mg/week), and compared them with 95 women of normal gestational age. The results showed that the risk of preterm delivery ( $<37$ weeks) more than doubled at high doses compared to low doses, consistent with the results of the Raikkonen et al. [97]. On the contrary, some scholars disagree with this result. Choi et al. [98] prospectively studied the pregnancy outcomes of 185 singleton pregnancies treated with over-the-counter preparations or naturopathic preparations containing glycyrrhiza during pregnancy, while 370 age-matched singleton pregnancies not exposed to any potential teratogen were taken as controls. The results showed that there was no difference between the main malformations and the control group [OR $=3.9,95 \% \mathrm{CI}$ $0.44-3.5, P=0.27$ ), and $91 \%$ of the exposed women used a higher dose of licorice, without an increased risk of preterm labor ( $<37$ weeks). Therefore, they believe that licorice is not a major teratogen or a risk factor for preterm birth. Differences in these results may be related to different types of exposure (diet and pharmaceutical formulations) or the amount of use or co-exposure factors. Therefore, glycyrrhizin was proposed as an antiviral drug, while dosage, form, and measurement should be considered in clinic. In addition, studies [99] have shown that glycyrrhizin can inhibit the activity of P450 enzyme and thus increase the serum drug concentration metabolized by the liver; therefore, the drug dose should be reduced appropriately when it combined with glycyrrhizin.

\section{Nanoparticle-mediated drug delivery}

Nanomaterials are defined as having at least one dimension between 1 and $100 \mathrm{~nm}$, although the definition is often relaxed in the pharmaceutical literature to encompass larger (submicron) structures several hundred nanometers across [100]. They show a variety of medical applications, in which the role of drug delivery has attracted the attention of scholars, especially in the field of antiviral therapy. Caster [101] turned the first-line drug for HIV into a nanomaterialNANOefavirenz and NANOlopinavir. Preclinical studies have shown that it is effective in inhibiting HIV-1 replication in terms of bioequivalence and can slow down the body's resistance to HIV-IIIB and type A viruses. Moreover, nanoparticle-mediated drug delivery (NMDD) can reduce the total dose while maintaining clinical efficacy, thus improving patient tolerance and reducing treatment cost. With the advantage of precise targeting and fewer side effects,
NMDD can be considered for use in pregnant women with COVID-19. In addition, nanomaterials can be used as vaccine adjuvants because of their superior biocompatibility, high bioavailability, and favorable biocompatibility. Yoon et al. have disclosed a nano-delivery system for SARS vaccine; they combined the SARS-CoV DNA vaccine (psi-S) that encodes $S$ protein with the polymer polyvinylamine (PEI), which effectively delivered psi-S into cells and induced antigenspecific humoral and cellular immune responses [102]. Therefore, the characteristics of nanomaterials effectively targeting specific sites can improve the immunogenicity of new vaccines, avoid primary clearance in the liver, and reduce its toxic side effects. It has broad prospects in the prevention and treatment of pregnant women with COVID-19.

Similarly, for pregnant women with COVID-19, the use of NMDD is an effective way to ensure that drugs can selectively target maternal disease without fear of teratogenic or other adverse effects on the fetus [103]. The ideal nanocarrier for the treatment of maternal disease should be one that is poorly bound to the placenta and can be rapidly absorbed by the maternal target organ, which can be achieved by constructing a NMDD with a large amount of cryptography and an optimal charge to ensure that placental attachment is avoided [103]. Most studies have shown that nanoparticles administered by the mother produce little or no fetal toxicity at drug concentrations. Wick et al. [104] reported that there was no negative effect on human placental viability (hCG, glucose consumption, and lactate production) and morphology when pregnant women are exposed to or ingested polystyrene $(50,80,240$, $500 \mathrm{~nm}$ ) nanoparticles during in vitro perfusion. Menjoge et al. [105] also failed to observe a negative effect on placental function by measuring biochemical and physiological indicators such as blood oxygen transfer rate and fetal venous flow in the same model. However, there are exceptions which seem to relate to the specific chemical composition of the material [106]. Therefore, we should also focus on the development of nanomaterials; make reasonable selection based on the composition of the preparation, potential biological distribution, toxicity, etc.; and give patients proper guidance. Taken together, NMDD will open the door to drug development programs that specialize in treating maternal diseases.

\section{Conclusions}

In recent years, the coronavirus has realized the jump from animals to human through the gene mutation, leading to the outbreak of epidemic many times, causing huge loss of people's lives and property. It is foreseeable that similar outbreaks and epidemics are inevitable in the future. Therefore, largescale investment in research and development of coronavirus vaccines and therapeutic drugs is needed. However, pregnant women are a group that cannot be ignored in drug 
development. Due to changes in anatomy, endocrine, and immune factors during pregnancy, they are prone to become the victims of viruses, especially in the case of outbreak of infectious diseases. According to the unique situation of pregnant women, we collected a lot of evidence for drug selection from the aspects of effectiveness and safety that can be used in the current COVID-19 treatment, including chloroquine and its analogues, drugs of HDT (Metformin, statins), lobinavir/ritonavir, glycyrrhizic acid, and NMDD. At the same time, we also provide some direction for today's drug research and development, such as drug target for ACE2, which is increased significantly in pregnancy women. Compounds that can block the binding of S protein and ACE2 is expected to be an effective drug for COVID-19. Of course, more carefully designed, large-scale trials are needed to verify the safety and efficacy of the drugs we have listed.

Acknowledgments The authors thank all patients for their participation. Special thanks are also extended to colleagues at the Zhejiang Chinese Medical University and Zhejiang University.

Funding information National Natural Fund Project

This work was supported by grants from the National Natural Science Foundation of China (No. 81973894).

\section{Compliance with ethical standards}

Conflict of interest The author declares that there are no conflicts of interest.

\section{References}

1. Organization. WH (2005) Statement on the second meeting of the International Health Regulations (2005) Emergency Committee regarding the outbreak of novel coronavirus (2019-nCoV)

2. Kwon JY, Romero R, Mor G (2014) New insights into the relationship between viral infection and pregnancy complications. Am J Reprod Immunol 71(5):387-390

3. Price ME, Fisher-Hoch SP, Craven RB, McCormick JB (1988) A prospective study of maternal and fetal outcome in acute Lassa fever infection during pregnancy. BMJ 297(6648):584-587

4. Jamieson DJ, Uyeki TM, Callaghan WM, Meaney-Delman D, Rasmussen SA (2014) What obstetrician-gynecologists should know about Ebola: a perspective from the Centers for Disease Control and Prevention. Obstet Gynecol 124(5):1005-1010

5. Fisk NM, Atun R (2009) Systematic analysis of research underfunding in maternal and perinatal health. BJOG 116(3): 347-356

6. Hui DS (2017) Epidemic and emerging coronaviruses (severe acute respiratory syndrome and Middle East respiratory syndrome). Clin Chest Med 38(1):71-86

7. Song Z, Xu Y, Bao L, Zhang L, Yu P, Qu Y, Zhu H, Zhao W, Han Y, Qin C (2019) From SARS to MERS, thrusting coronaviruses into the spotlight. Viruses 11(1)

8. Cui J, Li F, Shi ZL (2019) Origin and evolution of pathogenic coronaviruses. NAT REV MICROBIOL 17(3):181-192

9. Brian DA, Baric RS (2005) Coronavirus genome structure and replication. Curr Top Microbiol Immunol 287:1-30
10. Zhou Y, Jiang S, Du L (2018) Prospects for a MERS-CoV spike vaccine. Expert Rev Vaccines 17(8):677-686

11. Su S, Wong G, Shi W, Liu J, Lai A, Zhou J, Liu W, Bi Y, Gao GF (2016) Epidemiology, genetic recombination, and pathogenesis of coronaviruses. Trends Microbiol 24(6):490-502

12. Lu R, Zhao X, Li J, Niu P, Yang B, Wu H, Wang W, Song H, Huang B, Zhu N, Bi Y, Ma X, Zhan F, Wang L, Hu T, Zhou H, Hu Z, Zhou W, Zhao L, Chen J, Meng Y, Wang J, Lin Y, Yuan J, Xie Z, Ma J, Liu WJ, Wang D, Xu W, Holmes EC, Gao GF, Wu G, Chen W, Shi W, Tan W (2020) Genomic characterisation and epidemiology of 2019 novel coronavirus: implications for virus origins and receptor binding. LANCET 395(10224):565-574

13. Wrapp D, Wang N, Corbett KS, Goldsmith JA, Hsieh CL, Abiona O, Graham BS, McLellan JS (2020) Cryo-EM structure of the 2019-nCoV spike in the prefusion conformation. Science 367(6483):1260-1263

14. Yan R, Zhang Y, Guo Y, Xia L, Zhou Q (2020) Structural basis for the recognition of the 2019-nCoV by human ACE2. bioRxiv: 2020-2022

15. Lan J, Ge J, Yu J, Shan S, Zhou H, Fan S, Zhang Q, Shi X, Wang Q, Zhang L, Wang X (2020) Crystal structure of the 2019-nCoV spike receptor-binding domain bound with the ACE2 receptor. bioRxiv:2020-2022

16. EICKHOFF TC, SHERMAN IL, SERFLING RE (1961) Observations on excess mortality associated with epidemic influenza. JAMA 176:776-782

17. Creanga AA, Johnson TF, Graitcer SB, Hartman LK, Al-Samarrai T, Schwarz AG, Chu SY, Sackoff JE, Jamieson DJ, Fine AD, Shapiro-Mendoza CK, Jones LE, Uyeki TM, Balter S, Bish CL, Finelli L, Honein MA (2010) Severity of 2009 pandemic influenza A (H1N1) virus infection in pregnant women. Obstet Gynecol 115(4):717-726

18. Marx GF, Murthy PK, Orkin LR (1970) Static compliance before and after vaginal delivery. Br J Anaesth 42(12):1100-1104

19. Bayliss DA, Millhorn DE (1992,) Central neural mechanisms of progesterone action: application to the respiratory system. J Appl Physiol 73(2):393-404

20. Field SK, Bell SG, Cenaiko DF, Whitelaw WA (1991) Relationship between inspiratory effort and breathlessness in pregnancy. J Appl Physiol (1985) 71 (5):1897-1902

21. Toppozada H, Michaels L, Toppozada M, El-Ghazzawi I, Talaat M, Elwany S (1982) The human respiratory nasal mucosa in pregnancy. An electron microscopic and histochemical study. J Laryngol Otol 96(7):613-626

22. Bende M, Gredmark T (1999) Nasal stuffiness during pregnancy. LARYNGOSCOPE 109(7 Pt 1):1108-1110

23. Kourtis AP, Read JS, Jamieson DJ (2014) Pregnancy and infection. N Engl J Med 370(23):2211-2218

24. Pieper PG, Hoendermis ES (2011) Pregnancy in women with pulmonary hypertension. NETH HEART J 19(12):504-508

25. Nelson DM, Main E, Crafford W, Ahumada GG (1983) Peripartum heart failure due to primary pulmonary hypertension. OBSTET GYNECOL 62 (3 Suppl):58s-63s

26. Mor G, Cardenas I (2010) The immune system in pregnancy: a unique complexity. Am J Reprod Immunol 63(6):425-433

27. Silasi M, Cardenas I, Kwon JY, Racicot K, Aldo P, Mor G (2015) Viral infections during pregnancy. Am J Reprod Immunol 73(3): 199-213

28. Sykes L, MacIntyre DA, Yap XJ, Ponnampalam S, Teoh TG, Bennett PR (2012) Changes in the Th1:Th2 cytokine bias in pregnancy and the effects of the anti-inflammatory cyclopentenone prostaglandin 15-deoxy-Delta(12,14)-prostaglandin J2. Mediat Inflamm 2012:416739

29. Druckmann R, Druckmann MA (2005) Progesterone and the immunology of pregnancy. J Steroid Biochem Mol Biol 97(5):389396 
30. Muallem G, Wagage S, Sun Y, DeLong JH, Valenzuela A, Christian DA, Harms PG, Fang Q, Buza EL, Jain D, Elloso MM, Lopez CB, Hunter CA (2017) IL-27 limits type 2 immunopathology following parainfluenza virus infection. PLoS Pathog 13(1):e1006173

31. Danza A, Ruiz-Irastorza G, Khamashta M (2016) Pregnancy in systemic autoimmune diseases: myths, certainties and doubts. Med Clin (Barc) 147(7):306-312

32. Pazos M, Sperling RS, Moran TM, Kraus TA (2012) The influence of pregnancy on systemic immunity. Immunol Res 54(1-3): 254-261

33. Zoller AL, Schnell FJ, Kersh GJ (2007) Murine pregnancy leads to reduced proliferation of maternal thymocytes and decreased thymic emigration. IMMUNOLOGY 121(2):207-215

34. Kraus TA, Engel SM, Sperling RS, Kellerman L, Lo Y, Wallenstein S, Escribese MM, Garrido JL, Singh T, Loubeau M, Moran TM (2012) Characterizing the pregnancy immune phenotype: results of the viral immunity and pregnancy (VIP) study. J Clin Immunol 32(2):300-311

35. Klein SL, Passaretti C, Anker M, Olukoya P, Pekosz A (2010) The impact of sex, gender and pregnancy on 2009 H1N1 disease. Biol Sex Differ 1(1):5

36. Siston AM, Rasmussen SA, Honein MA, Fry AM, Seib K, Callaghan WM, Louie J, Doyle TJ, Crockett M, Lynfield R, Moore Z, Wiedeman C, Anand M, Tabony L, Nielsen CF, Waller K, Page S, Thompson JM, Avery C, Springs CB, Jones T, Williams JL, Newsome K, Finelli L, Jamieson DJ (2010) Pandemic 2009 influenza A(H1N1) virus illness among pregnant women in the United States. JAMA 303(15):1517-1525

37. Pierdominici M, Maselli A, Colasanti T, Giammarioli AM, Delunardo F, Vacirca D, Sanchez M, Giovannetti A, Malorni W, Ortona E (2010) Estrogen receptor profiles in human peripheral blood lymphocytes. Immunol Lett 132(1-2):79-85

38. Piccinni MP, Lombardelli L, Logiodice F, Kullolli O, Parronchi P, Romagnani S (2016) How pregnancy can affect autoimmune diseases progression? Clin Mol Allergy 14:11

39. Bharti B, Lee SJ, Lindsay SP, Wingard DL, Jones KL, Lemus H, Chambers CD (2015) Disease severity and pregnancy outcomes in women with rheumatoid arthritis: results from the Organization of Teratology Information Specialists Autoimmune Diseases in pregnancy project. J Rheumatol 42(8):1376-1382

40. Turner AJ, Hooper NM (2002) The angiotensin-converting enzyme gene family: genomics and pharmacology. Trends Pharmacol Sci 23(4):177-183

41. Donoghue M, Hsieh F, Baronas E, Godbout K, Gosselin M, Stagliano N, Donovan M, Woolf B, Robison K, Jeyaseelan R, Breitbart RE, Acton S (2000) A novel angiotensin-converting enzyme-related carboxypeptidase (ACE2) converts angiotensin I to angiotensin 1-9. Circ Res 87(5):E1-E9

42. Zisman LS, Keller RS, Weaver B, Lin Q, Speth R, Bristow MR, Canver CC (2003) Increased angiotensin-(1-7)-forming activity in failing human heart ventricles: evidence for upregulation of the angiotensin-converting enzyme homologue ACE2. CIRCULATION 108(14):1707-1712

43. Averill DB, Ishiyama Y, Chappell MC, Ferrario CM (2003) Cardiac angiotensin-(1-7) in ischemic cardiomyopathy. CIRCULATION 108(17):2141-2146

44. Hoffmann M, Kleine-Weber H, Krüger N, Müller M, Drosten C, Pöhlmann S (2020) The novel coronavirus 2019 (2019-nCoV) uses the SARS-coronavirus receptor ACE2 and the cellular protease TMPRSS2 for entry into target cells. bioRxiv:2020-2021

45. Yilin Z, Yandong N, Faguang J (2015) Role of angiotensinconverting enzyme (ACE) and ACE2 in a rat model of smoke inhalation induced acute respiratory distress syndrome. BURNS 41(7):1468-1477
46. Brosnihan KB, Neves LA, Anton L, Joyner J, Valdes G, Merrill DC (2004) Enhanced expression of Ang-(1-7) during pregnancy. Braz J Med Biol Res 37(8):1255-1262

47. Joyner J, Neves LA, Granger JP, Alexander BT, Merrill DC, Chappell MC, Ferrario CM, Davis WP, Brosnihan KB (2007) Temporal-spatial expression of ANG-(1-7) and angiotensinconverting enzyme 2 in the kidney of normal and hypertensive pregnant rats. Am J Physiol Regul Integr Comp Physiol 293(1): R169-R177

48. Levy A, Yagil Y, Bursztyn M, Barkalifa R, Scharf S, Yagil C (2008) ACE2 expression and activity are enhanced during pregnancy. Am J Physiol Regul Integr Comp Physiol 295(6):R1953R1961

49. Chen H, Guo J, Wang C, Luo F, Yu X, Zhang W, Li J, Zhao D, Xu D, Gong Q, Liao J, Yang H, Hou W, Zhang Y (2020) Clinical characteristics and intrauterine vertical transmission potential of COVID-19 infection in nine pregnant women: a retrospective review of medical records. Lancet

50. Davies JK, Shikes RH, Sze CI, Leslie KK, McDuffie RJ, Romero R, Gibbs RS (2000) Histologic inflammation in the maternal and fetal compartments in a rabbit model of acute intra-amniotic infection. Am J Obstet Gynecol 183(5):1088-1093

51. Salaun B, Romero P, Lebecque S (2007) Toll-like receptors' twoedged sword: when immunity meets apoptosis. Eur J Immunol 37(12):3311-3318

52. Madsen-Bouterse SA, Romero R, Tarca AL, Kusanovic JP, Espinoza J, Kim CJ, Kim J, Edwin SS, Gomez R, Draghici S (2010) ORIGINAL ARTICLE: the transcriptome of the fetal inflammatory response syndrome. Am J Reprod Immunol 63(1): 73-92

53. Deverman BE, Patterson PH (2009) Cytokines and CNS development. NEURON 64(1):61-78

54. Shi L, Smith SE, Malkova N, Tse D, Su Y, Patterson PH (2009) Activation of the maternal immune system alters cerebellar development in the offspring. Brain Behav Immun 23(1):116-123

55. Smith SE, Li J, Garbett K, Mirnics K, Patterson PH (2007) Maternal immune activation alters fetal brain development through interleukin-6. J Neurosci 27(40):10695-10702

56. Li CC, Wang XJ, Wang HR (2019) Repurposing host-based therapeutics to control coronavirus and influenza virus. Drug Discov Today 24(3):726-736

57. Roberts SS, Miller RK, Jones JK, Lindsay KL, Greene MF, Maddrey WC, Williams IT, Liu J, Spiegel RJ (2010) The ribavirin pregnancy registry: findings after 5 years of enrollment, 20032009. Birth Defects Res A Clin Mol Teratol 88(7):551-559

58. de Ruiter A, Taylor GP, Clayden P, Dhar J, Gandhi K, Gilleece Y, Harding K, Hay P, Kennedy J, Low-Beer N, Lyall H, Palfreeman A, O'Shea S, Tookey P, Tosswill J, Welch S, Wilkins E (2014) British HIV Association guidelines for the management of HIV infection in pregnant women 2012 (2014 interim review). HIV MED 15(Suppl 4):1-77

59. Colbers A, Greupink R, Burger D (2013) Pharmacological considerations on the use of antiretrovirals in pregnancy. Curr Opin Infect Dis 26(6):575-588

60. Plantone D, Koudriavtseva T (2018) Current and future use of chloroquine and hydroxychloroquine in infectious, immune, neoplastic, and neurological diseases: a mini-review. CLIN DRUG INVEST 38(8):653-671

61. Keyaerts E, Li S, Vijgen L, Rysman E, Verbeeck J, Van Ranst M, Maes P (2009) Antiviral activity of chloroquine against human coronavirus OC43 infection in newborn mice. Antimicrob Agents Chemother 53(8):3416-3421

62. Vincent MJ, Bergeron E, Benjannet S, Erickson BR, Rollin PE, Ksiazek TG, Seidah NG, Nichol ST (2005) Chloroquine is a potent inhibitor of SARS coronavirus infection and spread. Virol J 2: 69 
63. Keyaerts E, Vijgen L, Maes P, Neyts J, Van Ranst M (2004) In vitro inhibition of severe acute respiratory syndrome coronavirus by chloroquine. Biochem Biophys Res Commun 323(1):264 268

64. Li W, Moore MJ, Vasilieva N, Sui J, Wong SK, Berne MA, Somasundaran M, Sullivan JL, Luzuriaga K, Greenough TC, Choe H, Farzan M (2003) Angiotensin-converting enzyme 2 is a functional receptor for the SARS coronavirus. NATURE 426(6965):450-454

65. Lazzaroni MG, Dall'Ara F, Fredi M, Nalli C, Reggia R, Lojacono A, Ramazzotto F, Zatti S, Andreoli L, Tincani A (2016) A comprehensive review of the clinical approach to pregnancy and systemic lupus erythematosus. J Autoimmun 74:106-117

66. Silva JC, Mariz HA, Rocha LJ, Oliveira PS, Dantas AT, Duarte AL, Pitta IR, Galdino SL, Pitta MG (2013) Hydroxychloroquine decreases Th17-related cytokines in systemic lupus erythematosus and rheumatoid arthritis patients. Clinics (Sao Paulo) 68(6):766771

67. Wang M, Cao R, Zhang L, Yang X, Liu J, Xu M, Shi Z, Hu Z, Zhong W, Xiao G (2020) Remdesivir and chloroquine effectively inhibit the recently emerged novel coronavirus (2019-nCoV) in vitro. Cell Res 30(3):269-271

68. Klumpp TG (1965) Safety of chloroquine in pregnancy. JAMA $191(9): 765$

69. Kaplan YC, Ozsarfati J, Nickel C, Koren G (2016) Reproductive outcomes following hydroxychloroquine use for autoimmune diseases: a systematic review and meta-analysis. Br J Clin Pharmacol 81(5):835-848

70. Stockman LJ, Bellamy R, Garner P (2006) SARS: systematic review of treatment effects. PLoS Med 3(9):e343

71. Haagmans BL, Kuiken T, Martina BE, Fouchier RA, Rimmelzwaan GF, van Amerongen G, van Riel D, de Jong T, Itamura S, Chan KH, Tashiro M, Osterhaus AD (2004) Pegylated interferon-alpha protects type 1 pneumocytes against SARS coronavirus infection in macaques. Nat Med 10(3):290293

72. Loutfy MR, Blatt LM, Siminovitch KA, Ward S, Wolff B, Lho H, Pham DH, Deif H, LaMere EA, Chang M, Kain KC, Farcas GA, Ferguson P, Latchford M, Levy G, Dennis JW, Lai EK, Fish EN (2003) Interferon alfacon-1 plus corticosteroids in severe acute respiratory syndrome: a preliminary study. JAMA 290(24): 3222-3228

73. Moriguchi H, Sato C (2003) Treatment of SARS with human interferons. LANCET 362(9390):1159

74. Shalhoub S, Farahat F, Al-Jiffri A, Simhairi R, Shamma O, Siddiqi N, Mushtaq A (2015) IFN-alpha2a or IFN-beta1a in combination with ribavirin to treat Middle East respiratory syndrome coronavirus pneumonia: a retrospective study. J Antimicrob Chemother 70(7):2129-2132

75. Yazdani BP, Matok I, Garcia BF, Koren G (2012) A systematic review of the fetal safety of interferon alpha. Reprod Toxicol 33(3):265-268

76. van der Lee M, Sankatsing R, Schippers E, Vogel M, Fatkenheuer G, van der Ven A, Kroon F, Rockstroh J, Wyen C, Baumer A, de Groot E, Koopmans P, Stroes E, Reiss P, Burger D (2007) Pharmacokinetics and pharmacodynamics of combined use of lopinavir/ritonavir and rosuvastatin in HIV-infected patients. Antivir Ther 12(7):1127-1132

77. Chu CM, Cheng VC, Hung IF, Wong MM, Chan KH, Chan KS, Kao RY, Poon LL, Wong CL, Guan Y, Peiris JS, Yuen KY (2004) Role of lopinavir/ritonavir in the treatment of SARS: initial virological and clinical findings. THORAX 59(3):252-256

78. Lin S, Shen R, Guo X (2020) Molecular modeling evaluation of the binding abilities of ritonavir and lopinavir to Wuhan pneumonia coronavirus proteases. bioRxiv:2020-2021
79. Koss CA, Natureeba P, Plenty A, Luwedde F, Mwesigwa J, Ades V, Charlebois ED, Clark TD, Achan J, Ruel T, Nzarubara B, Kamya MR, Havlir DV, Cohan D (2014) Risk factors for preterm birth among HIV-infected pregnant Ugandan women randomized to lopinavir/ritonavir- or efavirenz-based antiretroviral therapy. J Acquir Immune Defic Syndr 67(2):128-135

80. Roberts SS, Martinez M, Covington DL, Rode RA, Pasley MV, Woodward WC (2009) Lopinavir/ritonavir in pregnancy. J Acquir Immune Defic Syndr 51(4):456-461

81. Kaufmann S, Dorhoi A, Hotchkiss RS, Bartenschlager R (2018) Host-directed therapies for bacterial and viral infections. Nat Rev Drug Discov 17(1):35-56

82. Huang C, Wang Y, Li X, Ren L, Zhao J, Hu Y, Zhang L, Fan G, Xu J, Gu X, Cheng Z, Yu T, Xia J, Wei Y, Wu W, Xie X, Yin W, Li H, Liu M, Xiao Y, Gao H, Guo L, Xie J, Wang G, Jiang R, Gao Z, Jin Q, Wang J, Cao B (2020) Clinical features of patients infected with 2019 novel coronavirus in Wuhan, China. LANCET 395(10223): 497-506

83. Zumla A, Hui DS, Azhar EI, Memish ZA, Maeurer M (2020) Reducing mortality from 2019-nCoV: host-directed therapies should be an option. LANCET 395(10224):e35-e36

84. Zumla A, Chan JF, Azhar EI, Hui DS, Yuen KY (2016) Coronaviruses - drug discovery and therapeutic options. Nat Rev Drug Discov 15(5):327-347

85. Beigel JH, Nam HH, Adams PL, Krafft A, Ince WL, El-Kamary SS, Sims AC (2019) Advances in respiratory virus therapeutics - a meeting report from the 6th isirv antiviral group conference. Antivir Res 167:45-67

86. Zmijewski JW, Lorne E, Zhao X, Tsuruta Y, Sha Y, Liu G, Siegal GP, Abraham E (2008) Mitochondrial respiratory complex I regulates neutrophil activation and severity of lung injury. Am J Respir Crit Care Med 178(2):168-179

87. Gilbert C, Valois M, Koren G (2006) Pregnancy outcome after first-trimester exposure to metformin: a meta-analysis. Fertil Steril 86(3):658-663

88. Li G, Zhao S, Cui S, Li L, Xu Y, Li Y (2015) Effect comparison of metformin with insulin treatment for gestational diabetes: a metaanalysis based on RCTs. Arch Gynecol Obstet 292(1):111-120

89. Fedson DS (2013) Treating influenza with statins and other immunomodulatory agents. Antivir Res 99(3):417-435

90. Pollack PS, Shields KE, Burnett DM, Osborne MJ, Cunningham ML, Stepanavage ME (2005) Pregnancy outcomes after maternal exposure to simvastatin and lovastatin. Birth Defects Res A Clin Mol Teratol 73(11):888-896

91. Zumla A, Azhar EI, Arabi Y, Alotaibi B, Rao M, McCloskey B, Petersen E, Maeurer M (2015) Host-directed therapies for improving poor treatment outcomes associated with the middle east respiratory syndrome coronavirus infections. Int J Infect Dis 40:7174

92. Kennedy DA, Lupattelli A, Koren G, Nordeng H (2016) Safety classification of herbal medicines used in pregnancy in a multinational study. BMC Complement Altern Med 16:102

93. Asl MN, Hosseinzadeh H (2008) Review of pharmacological effects of Glycyrrhiza sp. and its bioactive compounds. Phytother Res 22(6):709-724

94. Peiris JS, Chu CM, Cheng VC, Chan KS, Hung IF, Poon LL, Law KI, Tang BS, Hon TY, Chan CS, Chan KH, Ng JS, Zheng BJ, Ng WL, Lai RW, Guan Y, Yuen KY (2003) Clinical progression and viral load in a community outbreak of coronavirus-associated SARS pneumonia: a prospective study. LANCET 361(9371): 1767-1772

95. Goldstein JL, Silverstein FE, Agrawal NM, Hubbard RC, Kaiser J, Maurath CJ, Verburg KM, Geis GS (2000) Reduced risk of upper gastrointestinal ulcer complications with celecoxib, a novel COX2 inhibitor. Am J Gastroenterol 95(7):1681-1690 
96. Strandberg TE, Andersson S, Jarvenpaa AL, McKeigue PM (2002) Preterm birth and licorice consumption during pregnancy. Am J Epidemiol 156(9):803-805

97. Raikkonen K, Pesonen AK, Heinonen K, Lahti J, Komsi N, Eriksson JG, Seckl JR, Jarvenpaa AL, Strandberg TE (2009) Maternal licorice consumption and detrimental cognitive and psychiatric outcomes in children. Am J Epidemiol 170(9):1137-1146

98. Choi JS, Han JY, Ahn HK, Ryu HM, Kim MY, Chung JH, NavaOcampo AA, Koren G (2013) Fetal and neonatal outcomes in women reporting ingestion of licorice (Glycyrrhiza uralensis) during pregnancy. Planta Med 79(2):97-101

99. Li HY, Xu W, Su J, Zhang X, Hu LW, Zhang WD (2010) In vitro and in vivo inhibitory effects of glycyrrhetinic acid on cytochrome P450 3A activity. PHARMACOLOGY 86(5-6):287-292

100. De Jong WH, Borm PJ (2008) Drug delivery and nanoparticles: applications and hazards. Int J Nanomedicine 3(2):133-149

101. Caster JM, Patel AN, Zhang T, Wang A (2017) Investigational nanomedicines in 2016: a review of nanotherapeutics currently undergoing clinical trials. Wiley Interdiscip Rev Nanomed Nanobiotechnol 9(1)
102. Flemming A (2011) Vaccines: nano-adjuvant: double TLR stimulation is the key. Nat Rev Drug Discov 10(4):258

103. Keelan JA, Leong JW, Ho D, Iyer KS (2015) Therapeutic and safety considerations of nanoparticle-mediated drug delivery in pregnancy. Nanomedicine (Lond) 10(14):2229-2247

104. Wick P, Malek A, Manser P, Meili D, Maeder-Althaus X, Diener L, Diener PA, Zisch A, Krug HF, von Mandach U (2010) Barrier capacity of human placenta for nanosized materials. Environ Health Perspect 118(3):432-436

105. Menjoge AR, Rinderknecht AL, Navath RS, Faridnia M, Kim CJ, Romero R, Miller RK, Kannan RM (2011) Transfer of PAMAM dendrimers across human placenta: prospects of its use as drug carrier during pregnancy. J Control Release 150(3):326-338

106. Menezes V, Malek A, Keelan JA (2011) Nanoparticulate drug delivery in pregnancy: placental passage and fetal exposure. Curr Pharm Biotechnol 12(5):731-742

Publisher's note Springer Nature remains neutral with regard to jurisdictional claims in published maps and institutional affiliations. 